\title{
CONFABULANDO COM FÁBULAS
}

\author{
INÁCIO, Héllen Cristina Silva Aguiar ${ }^{1}$
} COSTA, Sueli Silva Gorricho ${ }^{2}$

\begin{abstract}
RESUMO: Esse trabalho, propõe uma reflexão acerca da atual situação do aluno-leitor e de sua competência leitora, além de apontar uma possível intervenção para incentivar o desenvolvimento da leitura polissêmica por meio do letramento literário. Objetiva defender que a Literatura é capaz de sensibilizar, inquietar e motivar um leitor inicial. E, para tanto, demonstra na prática como tornar possível tal atividade. Articulando com a teoria, expõe experiências de ensino e de leituras de fábulas, as quais resultaram na publicação de uma coletânea escrita pelos alunos. Fundamenta-se teoricamente na Análise da teoria literária, na Análise do Discurso francesa e na Teoria Bakhtiniana. Este trabalho demonstra ser possível a adaptação de um material didático às necessidades do aluno, e, a análise de obras literárias, com textos significativos, mesmo nas séries iniciais do Ensino Fundamental, possibilitando gestos interpretativos polissêmicos, os quais geram (re)escritas autorais, o que permite a assunção do sujeito-leitor a sujeito-autor. Adotou-se uma metodologia de pesquisa aplicada, numa abordagem qualitativa de natureza explicativa, além de sugestão de uma prática docente.
\end{abstract}

Palavras-chave: Literatura. Leitura. Interpretação. Autoria.

\section{CONFABULATING WITH TALES}

SUMMARY: This work proposes a reflection on the current situation of the student-reader and his reading competence, as well as pointing out a possible intervention to encourage the development of polysemic reading through literary literacy. It aims to defend that Literature is capable of sensitizing, disturbing and motivating an initial reader. And to do so, it demonstrates in practice how to make such an activity possible. Articulating with theory, it exposes teaching experiences and readings of fables, which resulted in the publication of a collection written by students. It is theoretically based on the Analysis of Literary Theory, the French Discourse Analysis and the Bakhtinian Theory. This work demonstrates that it is possible to adapt a didactic material to the needs of the student, and to analyze literary works, with significant texts, even in the initial grades of Elementary School, allowing for polysemic interpretive gestures, which generate (re) which allows the assumption of the subject-reader to subject-author. We adopted an applied research methodology, in a qualitative approach of an explanatory nature, besides pointing out an intervention that seeks to expose the results obtained from a teaching practice.

Keywords: Literature. Reading. Interpretation. Authorship.

\section{INTRODUÇÃO}

A leitura e a escrita estão presentes em todas as práticas sociais de uma sociedade, desde os primórdios da civilização, pois os indivíduos sempre sentiram a necessidade de registrar acontecimentos e conhecimento acumulados para deixar às futuras gerações. Por isso, hoje, cabe à escola, ambiente mais propício a isso, mesmo enfrentando desafios, o ensino eficiente dessa atividade.

Para ensinar a leitura e a escrita de forma eficaz, são necessárias práticas consistentes, ajustáveis e producentes para que todos os sujeitos-alunos envolvidos nesse processo sejam alcançados, Desenvolvendo assim, uma formação leitora e produtora textual. Possibilitando o acesso aos diversos

\footnotetext{
${ }^{1}$ Licenciada em Letras e Pedagogia pela Faculdade de Filosofia Ciências e Letras de Ituverava. Mestranda pela UFTM - MG

${ }^{2}$ Professora da Fundação Educacional de Ituverava. Faculdade de Filosofia Ciências e Letras.
} 
gêneros textuais, de modo que se desenvolva um leitor autônomo e crítico.

Como mediador e facilitador desse processo, o professor precisa encarar, de forma clara, a maneira como idealiza o ato de ler e norteia todas as suas outras ações de ensino na sala de aula. Por isso, que deve estimular seus alunos a buscar prazer na leitura e na escrita, sendo, antes de tudo, exemplo para eles.

O trabalho tem por objetivo propor uma reflexão com base na revisão teórica e demonstrar como a Literatura pode ser usada como estratégia para aquisição da leitura polissêmica e da escrita autoral nas séries iniciais do Ensino Fundamental. Ele exporá novas possibilidades de ensino utilizando um material norteado por textos literários infantis em uma proposta de trabalho previamente planejada e orientada pelo professor, a fim de atender as reais necessidades de seus alunos.

Assim, investiga como o movimento da leitura interpretativa afeta o movimento de escrita autoral dos alunos, e, para isso, reconstrói um trabalho dialógico com os clássicos da literatura. Analisando teoricamente a literatura infantil, principalmente, o gênero fábula, verifica-se como os sujeitos podem ser interpelados por estes, e como os reproduzem socialmente, podendo ser influenciados a construir outros sentidos; e assim, a partir de gestos interpretativos gerarem marcas autorais nos textos escritos.

Optou-se por essa temática, a fim de provar ser possível a aquisição da leitura interpretativa e da escrita autoral, logo nas primeiras séries do Ensino Fundamental, demonstrando que o material didático não limita o trabalho de um professor bem preparado; e que a opção de se trabalhar com textos literários infantis, além de contemplar questões morais e sociais, pode influenciar a construção discursiva do sujeito, dado que o sentido de um texto não está pronto, mas sim, a disposição do leitor para que este produza os seus sentidos de acordo com o meio ao qual está inserido e suas reais necessidades.

$\mathrm{Na}$ perspectiva escolar, a abordagem desse tema mostra-se muito relevante, pois a prática pedagógica cuidadosa, no que diz respeito à leitura, à interpretação e à produção de textos e sentidos, fomentando o desenvolvimento imaginário, literário e reflexivo do sujeito, permite à assunção do sujeitoaluno em sujeito-autor, a fim de que esse crie sentidos novos, saindo do campo da ideologia dominante, ou do senso comum.

Adotou-se a metodologia de pesquisa bibliográfica, numa abordagem qualitativa de natureza explicativa, além do apontamento de uma intervenção que relata por meio da observação os resultados obtidos, os quais pretendem provocar reflexões acerca das práticas de ensino de leitura e escrita na escola atual.

Dialogando com os estudos teóricos de Eagleton (1985), Coelho (2000), Bettelheim (1980), Cunha (1983), Colomer (2007), Zilberman (1988), Orlandi (1993), e Romão e Pacífico (1993). Esse trabalho está dividido em três seções. A primeira trata do processo de formação do leitor, iniciando a discussão apresentando a real condição dos leitores da escola atual e as perspectivas de progresso da aprendizagem literária, a partir dos processos de construção do leitor e dos sentidos.

A segunda seção, acorda como o letramento literário infantil pode ser uma alternativa de ensino da leitura polissêmica e como a escola pode ser um espaço privilegiado para o ensino da leitura literária infantil.

Já na terceira parte, defende-se a literatura infantil como um estímulo para a leitura e a escrita nas séries iniciais; e, demonstra isso por meio de uma proposta de trabalho especialmente desenvolvida para o quarto ano, de uma escola municipal do interior do Estado de São Paulo. Finalmente, apresenta-se as considerações finais. 


\section{A FORMAÇÃO LEITORA}

Desde a segunda metade do século XX, o Brasil vem sofrendo importantes transformações econômicas, políticas, sociais e culturais desencadeadas pelo capitalismo que deu lugar às sociedades pósindustriais. De acordo com Arendt (2004, p.137)

[...] (o consumismo) consistiu em tratar os objetos de uso como se fossem bem de consumo [...] A Revolução Industrial substituiu todo artesanato pelo labor; o resultado foi que as coisas do mundo moderno se tornaram produtos do labor, cujo destino natural é serem consumidas, ao invés de produtos do trabalho que se destinam a serem usados. [...] As horas gastas pelo animal laborans jamais são gastas em outra coisa senão em consumir; e quanto maior é o tempo de que ele se dispõe, mais ávidos e insaciáveis são os seus apetites. $\mathrm{O}$ fato de que estes apetites se tornam mais refinados, de modo que o consumo já não se restringe às necessidades da vida, não altera o caráter desta sociedade; acarreta o grave perigo de que chegará o momento em que nenhum objeto do mundo estará a salvo do consumo e da aniquilação através do consumo. (ARENDT, 2004, p. 137)

Em consequência disso, a sociedade moderna vivencia todos os desafios ocasionados pela pósmodernidade, que consiste-se em algo alienante que tem influenciado principalmente os adolescentes e jovens que, na ânsia serem reconhecidos e aceitos por esse novo modelo de sociedade, vivem um estereótipo fictício, uma vez que voltam-se para o capitalismo consumista. Essa situação tem influenciado a escola atual. Nota-se que a educação é regida conforme as necessidades da sociedade capitalista, e isso implica na concepção de indivíduos cada vez mais alienados, passivos, carentes de conhecimentos e socialmente marginalizado, tal como é comprovado pelo atual retrato social.

De acordo com os dados da Agência Brasil (2016), o IBGE de 2014 aponta haver cerca de 1,3 milhão de jovens entre 15 e 17 anos que deixam a escola sem concluir os estudos, dos quais $52 \%$ não concluiu sequer o ensino fundamental. Esse subgrupo vulnerável não exerceu seu direito à educação básica, fato que gera níveis de letramento baixíssimos, pois contribui para a precariedade da competência leitora, prejudicando a construção discursiva. Isso é refletido na inserção no mercado de trabalho, uma vez que a leitura além de ser um ato de sociabilidade, também é um ato emancipatório. (COLOMER, 2007, p. 51)

Entende-se que é dever da escola conduzir o aluno à leitura, mostrando uma nova maneira de se aproximar dos textos; mas, somente isso não o tem ajudado a tornar-se um leitor competente, articulando seu capital cultural com os novos sentidos produzidos pela suas leituras. Isso, caracteriza-se um problema social, e para tanto é urgente modificar essa situação.

De acordo com Fonseca (2010)

A leitura é um processo no qual se compreende a linguagem escrita. Nesta compreensão estão envolvidos o texto, sua forma e conteúdo, como o leitor, suas expectativas e conhecimentos prévios. Quando lemos um texto recorremos a tudo que já sabemos, isto é, cada componente do texto se relaciona, dialoga com o que já esta na nossa cabeça.

A leitura é um processo de interação entre leitor e texto. É o leitor que faz o texto ganhar sentido, pois as informações contidas no texto se articulam com as informações que o leitor já dispõe. Por isso, o olhar de cada leitor é diferente em função do seu repertorio, do que ele já sabe sobre o assunto.

Construir um leitor compete supõe construir alguém que compreenda o que lê, que possa aprender a ler também o que não esta escrito, identificando elementos implícitos, que estabeleça relações entre o texto que lê e outros já lidos, que sabe que vários sentidos são atribuídos a um texto, que consiga justificar e validar a sua leitura a partir dos elementos discursivos. (FONSECA, 2010) 
A formação do leitor começa com um acúmulo de práticas sociais que o rodeiam desde seu nascimento. Os primeiros contatos dão-se através de narrativas orais ou audiovisuais, bem como os livros impressos que já na primeira idade, colaboram na fixação das bases da educação literária da criança.

A aquisição dos sistemas simbólicos começa desde o nascimento, e possibilita que a criança entenda que as imagens e as palavras são representações de seu mundo, de suas experiências e da sua própria realidade. No início da aquisição narrativa, a criança se satisfaz reconhecendo e nomeando aquilo que vê nas imagens de um livro, o que leva a considerar a importância das ilustrações nos livros infantis. À medida que cresce, aumenta sua capacidade de entendimento, e, de intertextualizar o que é lido, produzindo sentido.

Applebee apud Colomer $(2007$, p.55, 56) menciona que as crianças são capazes de controlar certas estruturas narrativas como:

\begin{abstract}
$[\ldots]$ por exemplo, refere-se simplesmente, a uma associação de ideias entre os elementos, na qual uma ideia leva a outra sem mais relação. Aos cinco anos a maioria das crianças já utiliza a estrutura que Applebbe denominou "cadeia focalizada", na qual se estabelecem as peripécias de um personagem como um rosário de contas. Finalmente, lá pelos seis anos, meninos e meninas dominam propriamente a estrutura narrativa com todas as suas características, por exemplo, a de que o final deve ter relação com a proposta do inicio. [...]. A consciência narrativa inclui também as expectativas sobre a conduta dos personagens. Eles formam parte do mundo real das crianças e permanecerão em suas referências sobre a representação da realidade como uma herança cultural compartilhada com os adultos, que permitem experimentar a literatura como uma forma de cultura e sentir-se parte de uma comunidade de leitores, com as demais pessoas que estão próximas. (APPLEBEE apud COLOMER, 2007, p.55, 56)
\end{abstract}

Sendo assim, a leitura e a interpretação tem se mostrado mecanismos úteis e primordiais para o processo de construção dos sentidos, uma vez que os sentidos de um texto passam por processos de geração que inicia-se com o produtor, envolvendo as condições sociais, históricas, e ideológicas de produção, chegando ao leitor para ser interpretado, e reconstruído tornando-se presente e significativo, assim como atesta Koch e Elias (2010, p.21,22)

O sentido não está apenas no leitor, nem no texto, mas na interação autor-texto-leitor. [...] A pluralidade de leituras e de sentidos pode ser maior ou menor dependendo do texto, do modo como foi constituído, do que foi explicitamente revelado e do que foi implicitamente sugerido, por um lado; da ativação, por parte do leitor, de conhecimentos de natureza diversa [...] e de sua atitude cooperativa perante o texto, por outro lado (KOCK; ELIAS, 2010, p. 21-22)

Observa-se que, ao longo da vida, as experiências de leitura de uma pessoa sofrem alteração, pois se diferenciam entre si, uma vez que o processo de formação do leitor é contínuo, inacabado e extremamente influenciado por sua percepção de mundo. Ao texto atribui-se sentido no processo de leitura, por isso é fundamental que a pratica desta seja bem assistida no período certo para o letramento literário e bem dirigida pelo professor a fim de que os alunos atribuam sentido ao que se lê, fazendo associações a sentidos já existentes, podendo assim realizar uma leitura polissêmica, construindo seus próprios sentidos, mesmo não competindo ao leitor iniciante perceber de uma só vez todas as sutilezas de um texto. 
Eco apud Romão e Pacífico (2006, p. 27) afirma que

É pela interação entre o produtor do texto, o texto (incluindo suas condições de produção) e o leitor que o sentido se realiza. Assim sendo, inferimos que a leitura é um processo dialógico e intertextual muito mais amplo e abrangente do que a simples decodificação de um enunciado, pois, além da competência linguística para decodificar o texto, o ato de ler implica o aspecto interativo da linguagem, isto é, a existência do outro (autor) que interage com o leitor, que traz na memória uma história de leitura, um conhecimento intertextual, que ele armazena graças a uma enciclopédia semântica (ECO apud ROMÃO, PACÍFICO,2006, p. 27)

Assim sendo, o texto é um produto a ser interpretado, no qual o autor, usando sua competência leitora gera leituras previstas, de acordo com sua expectativa quanto a competência do leitor, que por sua vez, coopera para a atuação textual, produzindo os vários sentidos esperados por ele. Nesta concepção nota-se que o autor deixa de dominar exclusivamente o texto, pois percebe que o sentido não é construído por um único ponto de vista, ou fonte, e, sim, há muitas fontes que se cruzam na produção de um texto.

Logo há a necessidade de haver uma cumplicidade entre autor e leitor, sendo que esse atribuirá novos sentidos aos dizeres daquele, sendo influenciado por suas condições culturais, históricas e ideológicas, e são eles que atribuem imprevisibilidade aos sentidos podendo provocar leituras polissêmicas.

Orlandi (1993, p.43) explica as origens disso e aponta que

[...] as leituras já feitas de um texto e as leituras já feitas por um leitor compõe a história de leitura em seu aspecto previsível. Mas a história também é capaz de produzir a imprevisibilidade. Assim, é ainda do contexto histórico-social que deriva a pluralidade possível das leituras. (ORLANDI, 1993, p.43)

Por isso, entende-se também que o sentido seja histórico, pois não existiria se não houvesse fatos históricos, que reclamassem sentido, e que favorecessem sua existência. É somente na articulação e fusão dos fatores históricos, sociais e ideológicos, que se pode cristalizar os sentidos no ato da leitura, conforme comprovado por Romão e Pacífico (2006, p.29) explicam que

\begin{abstract}
A leitura acontece dentro de um processo histórico, que é também ideológico, vinculado a determinadas instituições sociais, que orientarão a direção que a leitura poderá tomar; o que é possível porque os leitores, de uma forma ou de outra, também, estão vinculados às instituições que já "aprenderam" como se deve interpretar os sentidos, que não são "livres", mas produzidos dentro das regras de determinadas formações ideológicas. (ROMÃO;PACÏFICO, 2006, p.29)
\end{abstract}

Assim, pode-se inferir que ideologia e a linguagem são indissociáveis e é por isso que, no âmbito escolar, é necessário proporcionar meios adequados e agradáveis para o exercício da leitura, da interpretação e da autoria, com o objetivo de propiciar ao leitor criar suas próprias leituras, pois é somente isso que legitima o homem como sujeito social pensante, crítico e analista e permite que este atue na realidade possuindo liberdade para compreender, criticar e alterar o seu mundo, permitindo-lhe sair de sua passividade.

Entretanto, esses objetivos de leitura não estão cristalizados na escola tradicional, pois se encontram dissimulados, estagnados nas mãos daqueles que detém o saber da sociedade capitalista que visa estabilizar o controle que exerce sobre a classe dominada. 
Para Zilberman e Silva (1998, p. 15)

[...] era imprescindível para a sociedade burguesa separar as duas facetas de um fenômeno comum, pois aproximar os sentidos educativos e mercantil associados a difusão da leitura denunciaria a função que desempenhava na direção do alargamento do mercado e controle dos indivíduos. Por sua vez, promover a identificação do leitor com o texto segundo um intercambio espontâneo e pessoal entre os dois redundaria em proporcionar ao primeiro uma experiência de liberdade e autonomia raramente julgada recomendável e conveniente pelo sistema em vigor. (ZILBERMAN; SILVA, 1988, p.15)

$\mathrm{Na}$ escola, percebe-se que os poucos textos lidos pelos alunos, em muito distanciam-se da realidade vivida por eles, e isso dificulta a espontaneidade da leitura, tornando-a uma tarefa cansativa, e alheia aos seus interesses. Algo que torna-se mais agravante em se tratando da escrita. Isso faz com que a leitura não seja motivada, pois o leitor não consegue enxergar a razão e a importância que ela desempenha, mesmo porque sempre haverá sentidos totalmente previsíveis; e sendo assim, ele a encara como uma obrigação, alienada às suas necessidades.

É por isso que esse trabalho busca no letramento literário razões para crer que a Literatura é uma alternativa para o ensino da leitura polissêmica, pois permite tornar real o imaginário, o improvável e a própria realidade do sujeito.

\section{O LETRAMENTO LITERÁRIO INFANTIL COMO ALTERNATIVA DE ENSINO DA LEITURA POLISSÊMICA}

Por se tratar de um instrumento de comunicação e interação social, a humanidade sempre recorreu à Literatura, utilizando imagens e signos linguísticos, para registrar fatos e histórias fixando-as através dos tempos. Cumprindo também o papel de transmitir conhecimento e cultura, ela retrata a realidade, sendo também resultado das relações dinâmicas entre o escritor, leitor e sociedade, pois é por meio de suas obras que o artista transmite seus sentimentos e percepção de mundo, levando seu leitor a refletir e até mesmo mudar seu posicionamento ideológico sobre a realidade que o cerca. Com isso, a Literatura também consiste-se em um dínamo no processo de transformação social.

Eagleton (1985, p. 1-17) afirma que a Literatura é uma forma de organização particular da linguagem, pois tendo uma linguagem auto referencial e um discurso não pragmático, consiste-se em uma escrita altamente valorativa e esclarecedora, a qual modifica a realidade observada, passando a criar uma realidade autônoma.

Embora não definida objetivamente, Eagleton (1985, p. 14) ainda explica que a atribuição desse conceito de Literatura depende da maneira pela qual alguém resolve ler um texto e não da natureza daquilo que é lido. Isso depende da ideologia de cada leitor e analista, pois uma obra que fora considerada filosófica no século XIX, hoje, pode-se atribuir a ela um caráter literário, dependendo da concessão de valores e ideologias a ela atribuída, ou seja, depende de quem lê, quando lê e como é encarado e aceito o que é lido.

O segredo está no modo como as pessoas as consideram. De acordo com Eagleton (1985, p. 15) "se [as pessoas] decidirem que se trata de Literatura, então, ao que parece o texto será literatura, a despeito do que o seu autor tinha pensado". Assim, pode-se dizer, que se está lidando com um texto dentro de um contexto social e histórico que se relaciona com o ambiente e interage com o mesmo. O fato de interpretar obras literárias à luz de ideologias e ser incapaz de atribuir a elas outras interpretações através de 
mudanças de valores, fazem com que certas obras conservem seu valor através dos tempos, como retoma Eagleton (1985, p. 17)

Se não é possível ver a literatura como uma categoria “objetiva”, descritiva, também não é possível dizer que a literatura é apenas aquilo que, caprichosamente, queremos chamar de literatura. Isso porque não há nada de caprichoso nesses tipos de juízos de valor: eles têm suas raízes nas estruturas mais profundas de crenças, tão evidentes e inabaláveis quanto o edifício Empire State. Portanto, o que descobrimos até agora não é apenas que a literatura não existe da mesma maneira que os insetos, e que os juízos de valores, que a constituem, são historicamente variáveis, mas que esses juízos têm, eles próprios, uma estreita relação com as ideologias sociais. Eles se referem, em última análise, não apenas ao gosto particular, mas aos pressupostos pelos quais certos grupos sociais exercem e mantêm o poder sobre outros. (EAGLETON, 1985, p.17)

O mesmo aplica-se a Literatura Infantil, que como objeto de estudo individualizado, origina-se no início do século XVIII, quando a criança legitimou seu lugar social de direito, deixando de ser equiparada ao adulto, tanto em sua condição física, quanto emocional. A partir de então, a criança passou a ter necessidades e características próprias, distanciando-se da vida adulta, e recebendo uma educação especial que a preparasse para tal. Utilizando da linguagem para inserir-se no meio social e expressar seus desejos e sentimentos, viu-se na produção literária infantil um aparato instrumental facilitador desse processo.

Nesse período, havia dois tipos de crianças: as da nobreza, e as das classes desprivilegiadas, as quais possuíam dois tipos de literatura muito diferentes. Estas, liam e ouviam histórias de cavalaria, aventuras, bem como lendas e contos folclóricos; enquanto, aquelas, eram orientadas por instrutores, lendo grandes clássicos.

Segundo Cunha apud Zilberman (2003, p.23)

Antes da constituição deste modelo familiar burguês, inexistia uma consideração especial para com a infância. Essa faixa etária não era percebida como um tempo diferente, nem o mundo da criança como um espaço separado. Pequenos e grandes compartilhavam dos mesmos eventos, porém, nenhum laço amoroso especial os aproximava. (CUNHA apud ZILBERMAN, 2003, p. 23)

Nos anos que se seguiram, houve muito interesse em se adequar uma literatura própria para a criança, pois viu-se a necessidade de atender às suas necessidades sociais. Com isso, surgiram duas tendências: a dos clássicos, os quais foram adaptados; e as do folclore, que houve a apropriação e o ajuste dos contos de fadas, que, definitivamente, não eram voltados para as crianças. Destacam-se nesse período autores consagrados universais como Charles Perrault, Jacob e Wilhelm Grimm, Esopo, bem como outros que foram surgindo com propostas de adaptações de obras literárias infantis, como Hans Christian Andersen, Carlo Collodi, Lewis Carroll, James Matthew Barrie, Mark Twain, Charles Dickens e Ferenc Molnar.

Já no Brasil, a literatura infantil surge informalmente com as obras pedagógicas e adaptações de produções portuguesas, representadas por Carlos Jansen, Figueiredo Pimentel, Coelho Neto, Olavo Bilac e Tales de Andrade. Mas, é com Monteiro Lobato que consolida-se uma literatura infantil brasileira mais cristalizada, mais especificamente com a obra "O Sítio do Pica-Pau Amarelo"; e este abriu caminho para muitos outros escritores.

De acordo com Coelho (2000, p. 122)

No Brasil, a partir de 1920, a Literatura infantojuvenil passa a ter um novo formato. 
Monteiro Lobato abre caminho para as inovações literárias infantojuvenis e mostra que o maravilhoso é possível de ser vivido por qualquer um. Misturando o imaginário com o cotidiano real em "Reinações de Narizinho", usando uma linguagem fluente, coloquial, objetiva, despojada e sem retórica e efabulação como em "A Menina do Narizinho Arrebitado". (COELHO, 2000, p. 122)

Desde então, pode-se destacar alguns escritores que também passaram a produzir obras literárias infantis, como Vinícius de Moraes, Cecília Meireles, Carlos Drummond de Andrade, Sylvia Orthoff, Ruth Rocha e Ziraldo. Não é possível ainda tratar de gêneros literários infantis devido a prematuridade desse tipo de texto, mas é possível falar em tendências literárias infantis, como a do realismo, a da fantasia (mesmo como questionamentos de problemas sociais), a do reaproveitamento do folclore e da exploração de fatos históricos. Mesmo assim, percebe-se que grande parte dessas produções permeiam aspectos pedagógicos, como atesta Cunha (1983, p. 27)

Ora, na medida em que tivemos diante de nos uma obra de arte, realizada através de palavras, ela se caracterizará certamente pela abertura, pela possibilidade de vários níveis de leitura, pelo grau de atenção e consciência a que nos obriga, pelo fato de ser única imprevisível - original, enfim, seja no conteúdo, seja na forma. Essa obra, marcada pela conotação e pela plurissignificação, não poderá ser pedagógica, no sentido de encaminhar o leitor para um ponto, uma única interpretação da vida.

A literatura infantil enquanto manifestação artística não é traição: apesar de ser sempre o adulto a falar a criança, se ele for realmente artista, seu discurso abrirá horizontes, proporá reflexão e recriação, estabelecera a divergência, e não a convergência. E suas verdadeiras possibilidades educativas estão ai. (CUNHA, 1983, p. 27)

Deve-se lembrar também que o fato de a literatura ser direcionada ao público infantil não a torna menos significativa ou reduzida artisticamente; esta continua sendo literária em sua essência atingindo tanto o público adulto como o público infantil, o que será alterado são suas concepções no que diz respeito a simplicidade de recursos, fato que não a torna menos valiosa. Como já mencionado, certas obras, feitas ou não para crianças, somente conseguem agradar-lhes se apresentarem determinadas características importantes para o prestígio do público infantil.

Para Drummond apud Cunha (1983, p. 71)

Certos espíritos dificilmente admitem que uma coisa simples pode ser bela, e menos ainda que uma coisa bela é necessariamente simples, em nada comprometendo a sua simplicidade as operações complexas que forem necessárias para realizá-la. Ignoram que a coisa bela é simples por depuração e não originariamente; que foi preciso eliminar todo elemento de brilho e sedução formal (coisa espetacular), como todo resíduo sentimental (coisa comovedora), para que somente o essencial permanecesse. E diante da evidente presença do essencial, não percebendo, até mesmo fugindo a ele, o preconceituoso procura o acessório, que não interessa e foi removido. Mas pura é a obra [...] (DRUMMOND, C. apud CUNHA, 1983, p.71)

Ser uma obra simples, não quer dizer que seja fácil; e, frequentemente, por provocar essa confusão, ela torna-se pueril. Por sua vez, a puerilidade gera o artificialismo o que pode ocasionar um distanciamento de seus leitores, dado que psicologicamente não se justifica esse estilo, uma vez que a criança cresce à medida em que vence obstáculos. E é justamente, essa dose de dificuldade que fará com que a criança se interesse, empenhe em resolver problemas e se desenvolva. Apresenta-se como uma de suas principais características além do tom moralizador, o qual é construído pelo autor que utiliza da trama para chegar a cristalizadas conclusões morais e éticas, a imaginação que permite à criança a retomada de sua liberdade que lhe é tolhida sempre pelos discursos autoritários de um adulto, podendo ser este até mesmo o próprio autor de uma obra. 
Cunha (1983, p. 29) defende a ideia de que a literatura infantojuvenil manipula um certo conceito de criança, ou de adulto, e age de acordo com uma imagem. "Criar um texto, criar uma imagem, não é refletir. É agir. É atuar no concreto. É executar uma ação. (CUNHA, 1983, p. 29) Assim, nesse sentido, a produção de livros infanto-juvenis pode construir modelos.

\subsection{A ESCOLA COMO ESPAÇO PRIVILEGIADO AO ENSINO DA LEITURA LITERÁRIA INFANTIL NA PERSPECTIVA DA POLISSEMIA}

A Literatura é uma forma específica de conhecimento que deve ser discutido e considerado a fim de que atinja um objetivo. A questão do ensino de literatura ou da leitura literária envolve o exercício das singularidades e das propriedades compositivas que constroem esse tipo particular de escrita.

É possível afastar uma série de equívocos que costumam estar presentes na escola em relação aos textos literários, ou seja, trata-los como expedientes para servir ao ensino das boas maneiras, dos hábitos de higiene, dos deveres do cidadão, dos tópicos gramaticais, das receitas desgastadas do prazer do texto, etc. Postos de forma descontextualizada, tais procedimentos pouco ou nada contribuem para a formação de leitores capazes de reconhecer as sutilezas, as particularidades, os sentidos, a extensão e a profundidade das construções literárias. (BRASIL, 1997, p. 37)

O texto literário proporciona um diálogo que envolve as invenções da linguagem, a expressão das subjetividades, os mecanismos ficcionais e procedimentos em que a razão, as referências, e situações do cotidiano se misturam. Para tanto, o texto literário precisa ter por base um trabalho incorporado às práticas cotidianas da sala de aula.O gênero literário infantil é o primeiro gênero textual com qual o aluno entra em contato logo nos primeiros anos escolares. Este possibilita o desenvolvimento do ato de ouvir, ajuda a desenvolver a cognição, o pensamento lógico, a atenção, a escuta, a memória, a observação, a criatividade, a imaginação, a sensibilidade, a reflexão, a criticidade, e as linguagens oral e escrita. Além disso, amplia o repertório cultural, o volume de escrita, e o vocabulário; permitindo também que o professor trabalhe com diferentes estratégias de leitura.

A presença da literatura na sala de aula possibilita um processo de alfabetização e letramento significativo, pois, além de possibilitar a formação intelectual e a descoberta dos inúmeros sentidos que podem ser produzidos pelo leitor a partir de um texto, propõe a criação de valores ideológicos de um sujeito, permitindo-lhe o desenvolvimento de sua criticidade. Porém, para que esses objetivos sejam atingidos é necessário colocar em prática as proposições de Bettelheim $(1980$, p.8) que explica que

Para que uma história realmente prenda atenção da criança, deve entretê-la e despertar a sua curiosidade. Contudo, para enriquecer a sua vida, deve estimular-lhe a imaginação: ajudá-la a desenvolver seu intelecto e a tomar claras suas emoções; estar em harmonia com suas ansiedades e aspirações; reconhecer plenamente suas dificuldades e, ao mesmo tempo, sugerir soluções para os problemas que a perturbam. (BETTELHEIM, 1980, p.8)

Para isso, é preciso que o professor esteja atento às suas práticas docentes que limitam a compreensão de quaisquer textos. Os textos literários, pelas suas características próprias, se abrem a diversas interpretações, pois mexem ao mesmo tempo com a imaginação e com a experiência dos leitores. Por isso, como explica Faria (2004, p.129)

A tarefa do professor é complexa, pois, ao insistir em evitar que o aluno leia erradamente determinadas passagens, pode sepultar qualquer iniciativa mais pessoal. Por outro lado, o 
expediente de deixar que a quantidade de livros lidos, por si mesma, faça um leitor melhor, pode incorrer num tipo de leitor que enxerga sempre as mesmas personagens e a mesma historia (o leitor não compartilha sua experiência com a do livro, apenas superpõe uma a outra). Os limites de intervenção devem ser observados em cada contexto, em cada livro, a partir das características de cada turma e, se possível de cada aluno. Os resultados dessa intervenção, por seu turno, também, são dificilmente mensuráveis. (FARIA, 2004, p.129)

Para Faria (2004), há algumas práticas de leitura que precisam ser consideradas: a leitura com predominância descritiva que baseia-se na ação do leitor em relação ao texto de maneira pontual, individualizando e promovendo uma ligação tênue entre os fatos; a leitura com predominância de paráfrase, a qual consiste-se no apego aos elementos mais concretos da narrativas; e a leitura autônoma, que pressupõe as inferências que o leitor precisa fazer para completar a história e produzir outras possibilidades além do percurso original, se respaldando no seu domínio pleno de produção de sentidos.

Segundo Leffa (1996, p. 1) "o processo de leitura envolve vários aspectos, incluindo não apenas características do texto e do momento histórico em que ele é produzido, mas também, características do leitor e do momento histórico em que o texto é lido". Porém, observando todo o contexto social, percebese que a escola ainda não tem reconhecido que a escrita é reflexo da leitura, mas, acreditam que o ato de ler consiste em interação, decodificação, apreensão de significados, e interpretação superficial do texto lido. Com isso, a leitura literária tornou-se ferramenta de repetição, sendo usada como artificio para o ensino de outros conteúdos, como a gramática normativa, por exemplo.

O ato de ler consiste, sobretudo, na produção de sentidos a partir daquilo com o que se interage. É preciso experimentar a polissemia, a metáfora, a leitura do arquivo e dos saberes de cada aluno, bem como a investigação das condições de produção dos sentidos e sua inserção histórica. Entende-se que o sentido é gerado no encontro dos discursos dos dois, autor e leitor, na sua relação, em relação a outro dizer. Somente dessa forma, será despertado no aluno o interesse pela leitura, pois perceberá que pode interagir com esse texto, gerando novos sentidos, e experimentando uma relação de cumplicidade com o autor, liberdade interpretativa, podendo ser evidenciada na escrita autoral.

Eco apud Romão e Pacífico (2006, p. 29) confirma isso ao dizer que

[...] um texto é um produto cujo destino interpretativo deve fazer parte do seu próprio mecanismo generativo: gerar um texto significa atuar segundo uma estratégia que inclui as previsões dos movimentos do outro. [...] O autor preverá um Leitor-Modelo capaz de cooperar para a atualização textual como ele, o autor, pensava e de movimentar-se interpretativamente conforme ele se movimentou gerativamente. (ECO apud ROMÃO, PACÍFICO, 2006, p. 29)

Para demonstrar tal concepção, percebe-se principalmente, na Literatura Infantil, aspectos estratégicos que propõe e preveem a formação da competência leitora interpretativa, abrindo possibilidades para a escrita autoral, logo nas primeiras séries do ensino fundamental. Tratando de experiências sentimentais, sensações, e situações fantasiosas e imaginárias, a literatura infantil "trabalha essas sugestões exteriores, associando às recordações do passado e informações armazenadas", a fim de que o leitor "socialize formas que permitam a compreensão dos problemas, configurando-se como ponto de partida para o conhecimento do real e de uma atitude libertadora". (ZILBERMAN, 2003, p.37)

Ao oferecer a leitura de textos literários a aluno das séries iniciais do ensino fundamental, o professor dá voz e vez ao aluno, pois permite que este produza os seus sentidos, "emancipando a humanidade de suas amarras naturais, sociais e religiosas", conforme esclarece Jauss (1994, p.46), e 
disponibiliza à criança assuntos de seu interesse moral, social e ético, já que o conteúdo das obras literárias são construídos a partir de reflexões moralizantes que contribuem para o desenvolvimento de seu próprio ser, podendo, assim como atesta Held (1980, p. 151-152)

$[\ldots]$

encontrar nela [na literatura] certa essência do ser humano, de qualquer ser humano, de si mesmo: tradução de necessidade, de angustias, de desejos, conscientes ou não. Verdade psicológica das personagens que devem possuir coerência interna, ser irmãs dos homens, mulheres, crianças que encontramos todos os dias, em todos os lugares[...] (HELD, 1980, p.151-152)

Além disso, permite que a criança projete-se nos personagens em diferentes situações, como por exemplo, as adversas situações de aflições, angústias, desafios, e tristeza; com as quais a criança também precisará aprender a lidar.

D`Onofrio (2005, p. 23) admite a plurifuncionalidade da Literatura

Assim entendida, a literatura teria, ao lado de sua função estética (como arte da palavra, expressão do belo através das palavras), uma função lúdica, na medida em que pode proporcionar prazer ao leitor; uma função cognitiva, porque traz conhecimento para o individuo, formando-o culturalmente, uma função pragmática, no sentido de que nenhum objeto cultural esta isento de ideologia e por isso prega essa ideologia; e uma função catártica, na qual p leitor purifica seus sentimentos, conforme já apontava Aristóteles, na sua obra Arte Poética. (D`ONOFRIO, 2005, p. 23)

Assim sendo, é necessário, que o professor proponha e possibilite situações de aprendizagem em que seus alunos, por meio de gestos interpretativos, desenvolvidos por meio de leituras polissêmicas, assumam autoria, a qual pode ser evidente em suas produções textuais orais e escritas.

Segundo Romão e Pacífico (2006, p. 21)

Chamamos a atenção para o fato de que, em geral, o arquivo dos alunos e professores restringe-se aos meios de comunicação de massa (em especial, programas televisivos) e ao livro didático, em um movimento parafrástico de repetí-los. Argumentos clonados em série, as mesmas respostas, exercícios que se repetem com espaços de preencher lacunas e/ou testes e/ou perguntas dirigidas indicam que o pântano enganoso da repetição se instala. Nesse corredor de atividades dirigidas de leitura - muitas das quais impostas por um sistema educacional orientador de grades curriculares, e não de janelas abertas a reflexão, crítica e emancipação política e estética de seus atores... (ROMÃO; PACÍFICO, 2006, p.21)

Em contrapartida, a literatura infantil é considerada como "a abertura para a formação de uma nova mentalidade" (COELHO, 2000, p. 27). Ela não tem por objetivo primário ensinar, mas ela faz parte da aprendizagem, pois é com ela que as crianças são introduzidas em um mundo de representações da realidade, a qual poderá ser observada, analisada e modificada.

É esse o caráter fundamental da Literatura: traduzir verdades individuais, de tal maneira integradas, na verdade geral e abrangente, que a forma representativa escolhida, mesmo perdendo, com o tempo, o motivo particular que a gerou, continua falando aos homens por outros motivos, também verdadeiros, no momento em que surgem. (COELHO, 2000, p. 39). 
Por esse motivo, defende-se que a Literatura é uma bem-sucedida alternativa de ensino da leitura polissêmica, pois tem a tarefa de servir como agente de formação crítica e reflexiva, se estimulada pelo ambiente escolar. A fim de defender essa premissa, fora desenvolvido uma proposta de trabalho que comprova que o letramento literário é uma alternativa eficaz para o ensino da leitura polissêmica na escola.

\title{
3 O GÊNERO LITERÁRIO FÁBULA COMO ESTÍMULO DA LEITURA E DA ESCRITA NAS SÉRIES INICIAIS
}

As fábulas, gênero literário milenar específico, tem se mostrado uma excelente estratégia para demonstrar que o letramento literário é uma alternativa para o ensino da leitura polissêmica e da escrita autoral nos anos iniciais do ensino fundamental, pois de forma simples consegue agregar em uma mesma prática todos os aspectos envolvido nesse processo.

Segundo Coelho (2000, p.165)

\begin{abstract}
As fábulas surgiram anonimamente e passaram a circular entre os povos da antiguidade, transformando-se com o tempo no que hoje conhecemos como tradição popular. De terra em terra, de região a região, foram sendo levadas por contadores de histórias, peregrinos, viajantes, povos emigrantes, etc. que acabaram por ser absorvidas por diferentes povos e, atualmente, representam fator comum entre diferentes tradições folclóricas. (COELHO, 2000, p.165-165)
\end{abstract}

Nascida no Oriente, e reinventada no Ocidente por um escravo grego chamado Esopo (século VI a. C.), e posteriormente, divulgadas por Fedro (15 a.C - 50 d. C) e Jean de La Fontaine (1621 - 1695), as fábulas, gênero textual do domínio discursivo literário, são compostas por narrativa curtas, atemporais, em prosa ou em verso, com linguagem culta ou coloquial, apresentando personificações de animais que pregam mensagens moralizantes, as quais apontam o modo mais sábio de agir nas mais diversas situações cotidianas enfrentadas.

Segundo La Fontaine, (1989, p. 39)

Somos a síntese do que há de bom e mal nas criaturas irracionais. As fábulas, portanto, é um quadro onde cada um de nós se acha descrito. O que elas nos apresentam confirma os conhecimentos hauridos em virtude da experiência pelas pessoas idosas e ensina às crianças o que convém que elas saibam. E como estas são recém chegadas neste mundo, não devemos deixá-las nessa ignorância senão durante o menor tempo possível. Elas têm que saber o que é um leão, o que é uma raposa, e assim por diante, portanto às vezes se compara o homem a um destes animais. Para isto servem as fábulas, pois é delas que provêm as primeiras noções desses fatos. (FONTAINE, 1989, p.39)

A fábula tem por objetivo denunciar a miséria, as injustiças, os desequilíbrios sociais e comportamentais dos indivíduos. Permite a interpretação de uma multiplicidade de sentidos, estimulando a discussão, realizando uma leitura polissêmica, pois o interdiscurso, as condições de produção, a ideologia e os fatores históricos podem conduzir o leitor a uma produção de diversos sentidos, possibilitando assim a fuga dos sentidos previamente estabelecidos por discursos detentores de poder. Somente aplicando todos esses preceitos o professor conseguirá atrair a atenção das crianças e estimular o gosto pela leitura. 


\subsection{A Fábula na Sala de Aula: Uma Proposta de Trabalho}

Para desenvolver a experiência de docência que atesta a premissa desse trabalho, optou-se por planejar e aplicar uma proposta de trabalho a alunos com dificuldade cognitivas e comportamentais do $4^{\circ}$ ano do Ensino Fundamental da Rede Municipal de Ensino, do interior do Estado de São Paulo. A proposta de trabalho com Fábulas permitiu ao professor aplicar as propostas planejadas que propunham desafios que aumentaram gradativamente o interesse pela leitura interpretativa e escrita autoral.

A seguir encontram-se discriminadas as etapas de desenvolvimento do projeto conforme foi aplicado:

\section{Etapas de desenvolvimento do projeto \\ Etapa 1: Apresentação do Projeto e Diagnóstico \\ Duração: 01 aula}

O trabalho foi iniciado com um pedido de tarefa de casa, o qual solicitava que a criança, juntamente com seus pais, relatassem algumas fábulas que conheciam, e trouxessem esses textos para escola na próxima semana. Na data marcada para entrega dessa atividade, foi feito um convite para um passeio pelo lago da cidade, onde foi realizada a apresentação do projeto. Nessa apresentação, foram compartilhados com os alunos os objetivos desse trabalho, e a previsão dos resultados pretendidos com ele. Foi esclarecido também que haveria diferentes momentos para reflexão, socialização, discussão e construção de novos conhecimentos. Após essa apresentação, os alunos foram questionados se conheciam algumas fábulas e foram incentivados, a se apresentarem e compartilharem o material que levaram.

Essa atividade teve por objetivo compreender os objetivos do projeto e comprometer-se com ele; conhecer as etapas do trabalho, promover a participação de familiares na realização do projeto; e ativar e ampliar o repertório dos alunos como sujeitos leitores e ouvintes atentos.

\section{Etapa 2: Leitura: Atividade de leitura colaborativa Duração: 02 aulas}

De volta à sala de aula, após realizar esse levantamento de conhecimento prévio, foram distribuídos mais alguns textos e livros para que fosse realizada, primeiramente, a leitura de maneira silenciosa, seguida pela leitura compartilhada em voz alta, e dramatizada de algumas fábulas mais conhecidas, como "A Formiga e a pomba", "O Menino que mentia", "A Lebre e a Tartaruga", "A Raposa e a Cegonha", e o "Leão e o Ratinho", "A rosa e a borboleta", "O cão e o osso", "O corvo e o jarro", e "O vento e o sol". Cada vez que o texto era lido, percebiam-se novas possibilidades de interpretação, as quais iam sendo comentadas pelos alunos, possibilitando a fruição literária, estabelecendo assim uma troca de sentidos entre autor-leitor-texto.

Tal prática trouxe a atenção dos alunos que há inúmeros tipos de texto, mas cada um permite diferentes maneiras de realização da leitura, pois estas devem ser feitas conforme o objetivo daquilo que é lido. Essa atividade teve por objetivo ampliar o repertório do aluno e desenvolver sua competência leitora.

\section{Etapa 3: Reflexão: Atividade com base na moral das fábulas Duração: 01 aula}

Depois da leitura realizada, foi discutido alguns pontos relacionados às lições que podem ser depreendidas desses textos. Os alunos puderam recontar e aplicar na realidade as lições de moral das fábulas lidas, sob o olhar interpretativo que tiveram. Kaufman e Rodriguez (1995, p.44) defendem que "ter 
contato com essa diversidade de textos é, obviamente, uma via efetiva para melhorar a competência comunicativa das crianças", pois isso auxilia no desenvolvimento da habilidade leitora e escrita.

Essa atividade teve por objetivo discutir a importância do conteúdo temático das fábulas, e os sentidos produzidos por ela.

\title{
Etapa 4: Estudo analítico e análise dos recursos linguísticos e discursivos das fábulas Duração: 02 aulas
}

Após essa atividade reflexiva, foi realizada atividades de pesquisa orientada, com material previamente selecionado, tanto impresso, quanto digital, a qual objetivava levar os alunos a conhecer e compreender a origem, o contexto histórico, e os principais autores das fábulas, além dos recursos expressivos na produção delas. Os alunos foram incentivados a compreender a estrutura do gênero fábula e os elementos que compõe essa narrativa, a saber, o tom de ensinamento, moral, crítica, enredo, personagens, e os momentos da narrativa.

Em grupos, por meio da leitura dos textos distribuídos, como a "A formiga e a pomba", "O Menino que mentia", e a "Rosa e a Borboleta", os alunos foram indicadas a ler, compreender e discutir as características formais da fábula previamente selecionada ao grupo, fazendo também exercícios de comparação das fábulas em versos e em prosa. Foram levantadas discussões sobre personagens, moral, e os objetivos das fábulas. Após a atividade, os alunos foram convidados a apresentar para a sala a fábula que leram e a comentar o que aprendeu das análises estrutural e interpretativa feitas.

Após todos se apresentarem, e sob a direção do professor, concluíram que a moral precisa ser parte integrante da história, pois se caracteriza como um recurso estético do texto e que os personagens podem ser seres animados ou inanimados, desde que tenham alguma característica que contribuam para o desenvolvimento da ação na narrativa.

\section{Etapa 5: Reescrita e revisão coletiva Duração: 01 aula}

Nesse momento, os alunos discutiram os sentidos produzidos a partir da interpretação das fábulas, e, coletivamente, reescreveram, ditando-a ao professor.

\section{Etapa 6: Leitura e comparação de diferentes versões de uma fábula e reescrita em dupla. Duração: 01 aula}

Os alunos compararam duas versões de uma mesma fábula que livremente escolheram, interpretando-a, e reescrevendo em duplas, focalizando elementos linguísticos, e fatores de coesão e coerência.

\section{Etapa 7: Reescrita e revisão em duplas.}

Duração: 02 aulas

Conhecendo os critérios avaliativos, os alunos escolheram e reescreveram a fábula, analisaram uma fábula bem escrita demonstrada pelo professor, revisaram coletivamente o texto de uma das duplas e corrigiram seus próprios textos, focando os aspectos discursivos.

\author{
Etapa 8: Finalização e avaliação \\ Duração: 02 aulas
}


Nesta etapa, o objetivo do trabalho foi alcançado. Os alunos escreveram a versão definitiva do texto, e o ilustraram. Prepararam o livro de fábulas, utilizando folha sulfite e papel-cartão para a capa, e prepararam a leitura expressiva para o evento de lançamento e divulgação a ser feito em uma noite exclusiva para tal atividade.

O projeto fora avaliado mediante a produção e a apresentação oral e escrita dos alunos. De maneira geral, analisando as (re)escritas dos alunos, percebeu-se que compreenderam a proposta do projeto, as características estruturais do gênero fábula, suas características discursivas, além de produzirem diversos outros sentidos, explícitos nas reescritas, a partir da análise da moral dos textos trabalhados. A autoria esteve presente nos textos reescritos. Embora tenham partido de um sentido comum, criaram, a partir do conhecido, seus próprios sentidos coesos e coerentes.

\section{CONSIDERAÇÕES FINAIS}

O trabalho apresentado é uma demonstração da importância do letramento literário como uma alternativa viável para o ensino da leitura polissêmica e da escrita autoral. Além disso, pôde mostrar que é possível desprender-se do livro didático, utilizando-se de outras possibilidades. Assim, o melhor material didático a ser utilizado na sala de aula é um professor bem preparado.

Ademais, demonstrou-se que com planejamento e orientação, o professor consegue facilitar o progresso de seus alunos, e assim, atingir seus objetivos, produzindo uma prática pedagógica segura. A leitura polissêmica do texto literário, no caso estudado com as fábulas, amplia o universo interpretativo com reflexões imprevistas, coesas e coerentes, favorecendo o aluno leitor a se tornar também autor de seus textos (re)escritos.

\section{REFERÊNCIAS}

ARENDT, H. A condição humana. 5 ed. Revisada. RJ: Forense Universitária, 2004.

AGÊNCIA BRASIL. Encceja Nacional tem 1,69 milhão de inscritos. Disponível em: agenciabrasil.ebc.com.br/educação/noticia/2016-02/2013-milhao-de-jovens-entre-15-e-17-anosabandonam-escola. Acesso em 10 de abril de 2018

BeTtelheiM, B. A Psicanálise dos contos de fadas. Rio de Janeiro: Paz e Terra, 1980.

BRASIL. Ministério da Educação Secretaria de Educaçao Fundamental. Parametros curriculares nacionais - 1 a 4 séries. Brasília. MEC/SEF, 1997.

COELHO, N.N. Literatura: arte, conhecimento e vida. São Paulo: Peirópolis, 2000.

COLOMER, T. Andar entre livros: a leitura literária na escola. Tradução: Laura Sandroni. SP: Global Editora, 2007

CUNHA, M. A. A. Literatura infantil: teoria e prática. São Paulo. Ática, 1983.

D’ONOFRIO, S. Teoria do texto. São Paulo: Ática, 2005. v. 1.

EAGLETON, T. Teoria da Literatura: uma introdução. Tradução: Waltender Dutra. São Paulo: Martins Fontes, 1985. 
FARIA, A.M. Como usar a literatura infantil na sala de aula. São Paulo: Contexto, 2004.

FONSECA, S.G. A importância da leitura para educação de jovens e adultos. 2010. Disponível em: recantodasletras.com.br/artigos-de-educacao/2243272. Acesso em 10 de abril de 2018.

HELD, J. O imaginário no poder: as crianças e a literatura fantástica. 3 ed. Tradução: Carlos Rizzi. São Paulo: Summus editorial, 1980.

JAUSS, H. R. A história da literatura como provocação à teoria literária. Tradução: Sergio Tellaroli. São Paulo: Ática, 1994.

KAUFMAN, A.M.; RODRIGUEZ, M.H.; Escola, leitura e produção de texto . Tradução: Inajara Rodriguez. Porto Alegre: Artes Médicas, 1995.

KOCH, I.V; ELIAS,V. M. Ler e compreender: os sentidos do texto. 3 ed.; 3 reimpressão. São Paulo: Contexto, 2010.

LA FONTAINE. Fábulas de La Fontaine. São Paulo. Ed. Edigraf Limitada, 1989. Ilustradas por Gustavo Doré. Antologia de tradutores, v.I e II.

LEFFA, V.J. Aspectos da leitura. Porto Alegre: Sagra - DC. Luzzatto, 1996.

ORLANDI, E. P. Discurso e leitura. São Paulo: Cortez; Campinas: Editora da Unicamp, 1993.

ROMÃO, L. PACÍFICO, S. Era uma vez uma outra história: leitura e interpretação na sala de aula. São Paulo: DCL, 2006.

ZILBERMAN, R.; SILVA, E.T. Leitura: por que a interdisciplinaridade? In: (Org.). Leitura: perspectivas interdisciplinares. São Paulo: Ática, 1988.

ZILBERMAN, R. A literatura infantil na escola. 11. ed. São Paulo: Global, 2003. 